\title{
Kernos
}

Revue internationale et pluridisciplinaire de religion grecque antique

$24 \mid 2011$

Varia

\section{Alexia PETSALIS-DIOMIDIS, Truly Beyond Wonders. Aelius Aristides and the Cult of Asklepios}

\section{Bruno Rochette}

\section{OpenEdition \\ Journals}

\section{Édition électronique}

URL : http://journals.openedition.org/kernos/1971

DOI : 10.4000/kernos. 1971

ISSN : 2034-7871

\section{Éditeur}

Centre international d'étude de la religion grecque antique

\section{Édition imprimée}

Date de publication : 1 janvier 2011

Pagination : 335-338

ISSN : 0776-3824

\section{Référence électronique}

Bruno Rochette, «Alexia petsalis-diomidis, Truly Beyond Wonders. Aelius Aristides and the Cult of Asklepios », Kernos [En ligne], 24 | 2011, mis en ligne le 17 octobre 2011, consulté le 21 septembre 2020. URL : http://journals.openedition.org/kernos/1971 ; DOI : https://doi.org/10.4000/kernos.1971 
France tout court. De la même façon, les contributions du volume ici présenté font écho aux divers aspects de la personnalité d'Aphrodite, depuis ses premières mentions à l'époque archaïque jusqu'à sa réception dans nos sociétés contemporaines.

À cet égard, le présent ouvrage représente un travail considérable et un outil de recherche de pointe, doté d'une ample bibliographie et de très utiles index thématiques et géographiques, qui s'ajoutent aux nombreuses références textuelles et iconographiques regroupées en fin de volume.

Iwo Slobodzianek

(Université de Toulouse - Le Mirail)

\section{Alexia Petsalis-Diomidis, Truly Beyond Wonders. Aelius Aristides and the Cult of Asklepios, Oxford, Oxford University Press, 2010. 1 vol. 19,5 cm $\times 25 \mathrm{~cm}, 315 \mathrm{p}$. (Oxford Studies in Ancient Culture and Representation). ISBN : 978-0-19-956190-2.}

Les Discours sacrés (Hieroi Logoi) [DS] d'Aelius Aristide, où l'orateur décrit sa relation passionnée avec le dieu guérisseur Asclépios, qui débute en décembre 144, sont des textes déconcertants à plus d'un titre. Ces discours, qui se présentent sous la forme d'un journal intime, offrent un intérêt au moins pour trois catégories de spécialistes. L'historien de la littérature y trouve un exemple significatif de récit autobiographique, l'historien des religions un témoignage de première main sur le fonctionnement d'un grand sanctuaire du monde grec, l'Asclépieion de Pergame, les psychologues une expérience religieuse singulière et des récits de rêves transcrits par le « rêveur» lui-même dont on peut tirer une interprétation psychanalytique ${ }^{1}$. La présente étude concernera surtout - mais pas exclusivement - l'historien de la religion grecque, puisque son sujet est le sanctuaire d'Asclépios à Pergame et l'expérience très particulière qu'y fit un pèlerin d'exception, Aelius Aristide. On admet en effet que l'analyse des $D S$ constitue un élément important pour la compréhension de la religion et de la culture propres au courant de la Seconde Sophistique, mais on ne s'accorde toujours pas sur le sens dans lequel doit aller l'exégèse de ce texte déroutant qui occupe une place à part dans l'œuvre d'Aristide. L'approche adoptée ici consiste à explorer les difficultés du texte d'Aelius Aristide en le replaçant dans le contexte dans lequel il a vu le jour. Les $D S$ sont en effet profondément enracinés dans les préoccupations culturelles de la Seconde Sophistique, dont la religion constitue un aspect fondamental. L'ouvrage remet en cause la distinction dichotomique, simpliste et absolue, élite/ peuple, que certains auteurs présentent comme caractéristique de la religion et la culture de cette époque. Il prend en considération non seulement les sources que l'on considère traditionnellement comme émanant de l'élite, mais aussi les genres populaires, comme les textes paradoxographiques et physiognomoniques (notamment Antonius Polémon de Laodicée [vers 88144]), considérés dans l'Antiquité comme faisant partie intégrante de la culture au sens large du terme, bien au-delà de l'intérêt populaire. La lecture des $D S$ proposée ici met en relation le corps, le voyage et le miracle (thauma), trois traits caractéristiques de la Seconde Sophistique. Une telle interprétation permet aussi d'établir un lien avec le début du christianisme et la culture byzantine, où ces trois éléments sont souvent intimement liés, comme par exemple dans le récit des miracles de la protomartyre sainte Thècle ( $\mathrm{I}^{\mathrm{er}} \mathrm{s}$. - texte du Ve s.) et de saint Artémios $\left(I V^{e} s .-\right.$ texte du VIe s.) et dans la pratique de plus en plus fréquente du pèlerinage. Même s'il convient de se méfier de jugements fondés sur des similitudes superficielles qui ne reflèteraient pas la nature exacte des expériences du peuple, on ne peut nier que la religion gréco-romaine et le christianisme sont des phénomènes contemporains, du II ${ }^{\mathrm{e}} \mathrm{s}$. jusqu'au Ve s., et qu’ils se sont développés dans la même partie du monde. Même s’il y a des différences dans la façon dont le

${ }^{1}$ G. Michenaud, J. Dierkens, Les rêves dans les ,Discours Sacrés' d'Aelius Aristide. IIe s. ap. J.-C. Essai d'analyse psychologique, Bruxelles, 1972. 
miracle est conçu par le monde gréco-romain et par le christianisme, on n'enregistre pas de divergences fondamentales durant les premiers siècles de notre ère. Malgré les progrès réalisés dans l'étude du pèlerinage dans le monde gréco-romain, ce phénomène dans la religion du temps continue de ne pas être reconnu comme tel. Ce concept est considéré comme n'ajoutant que peu de chose à notre connaissance de la pratique religieuse de l'Antiquité. On considère de surcroît qu'il est faussé par l'application du modèle chrétien, plus tardif. Loin d'interpréter les différents témoins séparément l'un de l'autre (textes, inscriptions, vestiges archéologiques), cette étude les a mis en relation en vue de reconstituer l'expérience des pèlerins. Le voyage, l'arrivée dans le sanctuaire, les activités à cet endroit et le chemin de retour sont considérés comme différentes étapes d'un processus complet et d'une expérience religieuse totale.

Le modèle du pèlerinage n'est toutefois pas indispensable pour comprendre l'expérience d'Aelius Aristide. On peut aussi prendre le parti de considérer la relation d'Aristide et d'Asclépios comme une histoire relative au corps, au voyage et à la religion qui a pour cadre l'Orient grec durant l'Empire romain. Les textes ne sont pas utilisés dans le sens historique traditionnel pour en extraire des détails topographiques et chronologiques. Leur rhétorique est analysée avec l'intention de définir des aspects de la culture et de la religion du $\mathrm{II}^{\mathrm{e}} \mathrm{s}$. L'ouvrage tient en outre compte des progrès réalisés durant les dernières décennies dans le domaine de l'histoire de l'art. Il prend en considération un large éventail de documents figurés traditionnels, comme l'architecture et la sculpture, mais aussi les monnaies et les inscriptions votives. Le livre propose donc une sorte d'itinéraire circulaire vers les $D S$ et l'Asclépieion de Pergame pour les interpréter dans le contexte culturel adéquat. Les deux premiers chapitres ne concernent pas directement les $D S$, mais placent le décor, en explorant la nature des écrits contemporains de polémique religieuse et en analysant le discours sur le corps et le voyage. Le troisième chapitre a quant à lui directement trait aux $D S$, tandis que les deux derniers examinent les aspects matériels du pèlerinage d'Aristide, c'est-à-dire l'archéologie et l'épigraphie de l'Asclépieion de Pergame.

Le chapitre 1 concerne la polémique religieuse. Il y est question d'un cas d'espèce qui montre les difficultés d'interprétation des sources littéraires et iconographiques relatives à la religion de cette époque : l'étude du culte du serpent miraculeux Glykon, le nouvel Asclépios, qui a connu une grande vogue durant le II ${ }^{\mathrm{e}}$ s., à Abonotichos, sur les bords de la mer Noire, et dont les monnaies témoignent de la popularité. D'après cette analyse, il n'est pas possible de prendre pour argent comptant ce que Lucien écrit dans son opuscule intitulé Alexandre ou le Faux Prophète sur les événements qui eurent lieu à Abonotichos. La dichotomie élite/peuple que l'on trouve dans cet opuscule constitue un aspect de la polémique de Lucien plutôt qu'une réflexion objective sur la situation sur le terrain. La mise en contexte de l'Alexandre parmi d'autres écrits polémiques sur la religion et des témoignages matériels du culte à l'intérieur des traditions iconographiques d'Asclépios montrent qu'il s'agit fondamentalement d'un culte traditionnel de ce dieu et que l'histoire qui en ressort n'est pas un récit opposant la religion de l'élite et la religion populaire, mais bien celui d'un pèlerinage religieux exégétique par opposition à un pèlerinage charismatique.

Le chapitre 2 examine les discours sur le corps et le voyage qui peuvent se révéler être des clés de lecture pour une meilleure compréhension des DS. La première section concerne le corps dans la culture gréco-romaine. Elle met l'accent sur la façon de voir et de lire le corps, les moyens qui permettent de localiser l'identité dans le corps et la façon dont est présenté le corps dans des récits autobiographiques. Il s'agit de déterminer quel sens il faut donner à l'expérience de la maladie et au rôle de ces processus dans la construction de l'identité. Une série de textes sont examinés : les romans, des dialogues de Plutarque ainsi que des écrits médicaux et physiognomoniques. La deuxième partie se concentre sur les textes et les images du paysage et du voyage et explore les structures qui leur servent de soubassement. Un nombre de thèmes com- 
muns émergent à la fois dans le discours relatif au corps et au voyage, en particulier la structure de l'énumération et de la mensuration, la rhétorique de la technè et sa combinaison paradoxale avec la présentation de l'auteur/praticien à la façon d'un theios aner et dans la construction des thaumata. Un aspect-clé des discours sur le corps et le voyage émerge dans leur rôle dans la création de récits narratifs et autobiographiques. La troisième section de ce chapitre revient sur les $D S$ en mettant l'accent sur la combinaison des thèmes du voyage, du corps et du récit autobiographique.

Le chapitre 3 concerne plus directement les $D S$. Il présente l'idée que ce texte est une façon très sophistiquée de lier le contact personnel et charismatique avec la divinité, enraciné dans le corps, avec les ambitions traditionnelles d'un membre de l'élite, comme la progression sociale et les succès oratoires. Loin d'être un écrit personnel déconcertant, les $D S$ apparaissent comme un texte autobiographique fermement enraciné dans les courants culturels du II ${ }^{\mathrm{e}} \mathrm{s}$. Son originalité réside dans le fait qu'y sont réunis le corps, le voyage et les miracles dans une présentation apologétique forte de l'auteur comme un theios aner d'un nouveau style, un modèle que l'on retrouvera dans le christianisme primitif et dans la culture byzantine.

Les chapitres 4 et 5 concernent le contexte matériel dans lequel se développe la relation d'Aristide avec Asclépios. L'Asclépieion de Pergame avait seulement comme rivaux les sanctuaires du même dieu à Épidaure et à Cos. À Pergame, les vestiges archéologiques et épigraphiques sont très riches. Le chapitre 4, divisé en deux sections, offre une lecture de la disposition spatiale du sanctuaire, lequel connut un important programme de constructions durant le $\mathrm{II}^{\mathrm{e}} \mathrm{s}$. La première partie explore la culture et l'ambiance du sanctuaire qui rassemblait des personnes malades et guéries miraculeusement. Les témoignages comprennent des ensembles littéraires dans le genre paradoxographique, des références à des recueils de mirabilia datant de l'Empire et des témoignages relatifs aux thaumata dans les temples. L'ensemble des sources analysées dans cette section s'oppose à l'idée dichotomique élite/peuple. La seconde section consiste en un examen détaillé des vestiges archéologiques du sanctuaire et en une interprétation du programme de constructions du II s. L'Asclépieion de Pergame est interprété comme une structure au sein de laquelle se déploie l'expérience de la maladie et de la guérison miraculeuse. Le chapitre 5, qui concerne l'interprétation de l'espace, se concentre sur les pèlerins. On y trouve un examen des rituels de l'incubation d'après la lex sacra du II $\mathrm{s}$. (dont on a conservé 36 lignes, où il est précisément question des rites de l'incubation $)^{1}$ et une analyse des offrandes votives pourvues de motifs sculptés et d'inscriptions. L'interprétation de la lex sacra, mise en relation avec l'architecture du sanctuaire, repose sur des études anthropologiques consacrées au pèlerinage. Les dédicaces votives sont ensuite analysées comme des récits autobiographiques du contact personnel du pèlerin avec le divin, en faisant un usage des analyses des discours sur le corps et le voyage développées dans les chapitres deux et trois. L'accent est placé sur la façon dont le corps du pèlerin guéri miraculeusement est évoqué dans le texte et l'image, sur l'effet de la manifestation commune des offrantes votives à l'intérieur du sanctuaire et sur l'expérience du pèlerin qui les lit. Tout ce chapitre comporte un examen de la tension entre le rôle et l'identité du groupe de pèlerins vu comme un tout et ceux de l'individu à la recherche d'une rencontre personnelle et d'une guérison miraculeuse.

L'étude est originale à plus d'un titre. Sa caractéristique majeure est certainement qu'elle est pluridisciplinaire et qu'elle examine tous les témoignages relatifs aux pèlerinages à Pergame au $\mathrm{II}^{\mathrm{e}} \mathrm{s}$. en les mettant en relation les uns avec les autres : textes littéraires, inscriptions, monnaies, sculptures, vestiges archéologiques. On saluera cet effort visant à décloisonner des disciplines qui sont généralement séparées, en particulier la philologie et l'archéologie. Mais ce n’est pas

${ }^{1}$ M. WÖrRLE, « Die Lex Sacra von der Hallenstrasse (Inv. 1965, 20) », in Chr. HABICHT, Altertümer von Pergamon VIII/3 (Die Inschriften des Asklepieions), Berlin, 1969, p. 167-190. 
tout. Les textes sur la religion ont été généralement étudiés de façon un peu simpliste sans tenir assez compte de leur nature normative et du contexte hautement polémique dans lequel ils ont été écrits. La présentation que font un Plutarque ou un Pausanias de la religion de l'élite et la caricature de la religion populaire d'un Lucien ont été acceptées comme deux faces d'une même pièce de monnaie. Les $D S$ ne peuvent rentrer dans ce moule, car ils sont le reflet à la fois de la religion de l'élite et de faits appartenant à la religion populaire. On a eu tendance à considérer ce texte comme une aberration au sein de l'œuvre d'Aelius Aristide. Ce n'est pas exagéré de dire qu'Aelius Aristide est souvent vu comme un illuminé. En confrontant les différents types de sources, la présente analyse propose une nouvelle façon de comprendre la religion du $\mathrm{II}^{\mathrm{e}} \mathrm{s}$. et montre que le texte d'Aristide, loin d'être un intrus dans ce contexte, s'adapte parfaitement aux mouvements religieux et culturels de son époque. Une fois accepté le fait que le texte d'Aristide s'insère dans des courants religieux et culturels plus larges, les $D S$ plaident de façon éloquente contre une dichotomie simpliste et absolue entre la religion de l'élite et la croyance populaire. Cette réhabilitation des $D S$, trop longtemps considérés comme des textes marginaux, ouvre de nouvelles voies pour une analyse renouvelée de ce texte fascinant. En particulier, la relation des $D S$ avec le reste de l'œuvre d'Aristide a été trop peu explorée. Dans l'autre sens, les vestiges matériels du sanctuaire de Pergame bénéficient eux aussi d'un nouvel éclairage grâce à une lecture réorientée du texte d'Aristide. Les $D S$ suggèrent une vie religieuse très riche à l'intérieur du sanctuaire et, en même temps, un haut degré de liberté et d'improvisation en dépit des règles précises données par la lex sacra.

Le pèlerinage thérapeutique, loin d'être une activité marginale, constitue un phénomène de grande ampleur dans la culture gréco-romaine. Cette importance est prouvée non seulement par le récit d'un pèlerin comme Aelius Aristide, mais aussi par les dépenses consenties par la cité pour reconstruire le sanctuaire d'Asclépios à Pergame. Si le pèlerinage est un aspect important de la vie religieuse, la religion est une composante essentielle de la Seconde Sophistique et un élément qui permet de définir l'identité grecque dans la mesure où la nature profonde et personnelle de l'expérience religieuse constitue un aspect significatif de l'identité. Les DS ont donc été envisagés pour ce qu'ils peuvent révéler sur la place centrale occupée par la religion dans le milieu culturel et social de la Seconde Sophistique.

La figure d'Aelius Aristide et le sanctuaire d'Asclépios à Pergame ont permis une étude de faits plus larges concernant la religion et la culture. L'examen d'éléments tels que l'expérience religieuse, le corps, la maladie et le voyage dans le cadre de la culture de la Seconde Sophistique a montré combien les faits antiques sont différents des phénomènes contemporains. On pourra peut-être regretter que l'approche proprement philologique du texte des DS soit absente. Il y a certainement beaucoup à découvrir par l'étude du vocabulaire de l'expérience religieuse personnelle employé par Aelius Aristide, comparé à celui d'autres auteurs. Quoi qu'il en soit, il s'agit d'un travail de qualité qui contribue à revoir l'image religieuse du $\mathrm{II}^{\mathrm{e}} \mathrm{s}$, défini tantôt comme un "âge de foì, un «temps d'anxiété », une "époque d'irrationalisme »1. L'ouvrage, qui est richement illustré ( 1 carte, 83 illustrations dans le texte et 4 planches hors texte en couleur), est doté d'une bibliographie fort complète ${ }^{2}$, d'un index des notions et des noms propres et d'un index locorum.

Bruno Rochette (Université de Liège)

1 R. LANE FOX, Païens et chrétiens. La religion et la vie religieuse dans l'Empire romain de la mort de Commode au Concile de Nicée. Traduit de l'anglais par R. Alimi, M. Montabrut et E. Pailler, Toulouse, 1997, p. 69-72.

2 On peut ajouter W.V. Harris, B. Holmes (éds), Aelius Aristide between Greece, Rome and the Gods, Leiden/Boston, 2008. 